\title{
Analysis of Empirical Relationships to Estimate the Runout Length of Fine-Grained Materials Flows
}

\author{
Chiara Cesali ${ }^{1 *}$ and Francesco Federico ${ }^{2}$ \\ ${ }^{1}$ Ph.D. Student, Department of Civil Engineering and Information Engineering, University of Rome "Tor Vergata", Rome, Italy \\ ${ }^{2}$ Associate Professor of Geotechnics, Department of Civil Engineering and Information Engineering, University of Rome "Tor Vergata", Rome, \\ Italy \\ *Corresponding Author: Chiara Cesali, Ph.D. Student, Department of Civil Engineering and Information Engineering, University of Rome \\ "Tor Vergata", Rome, Italy.
}

Received: May 27, 2019; Published: July 08, 2019

DOI: $10.31080 /$ ASAG.2019.03.0562

\begin{abstract}
Owing to the appreciable variability of results in the prediction of the runout length of granular flows, the empirical relationships with difficulty may provide preliminary reliable estimations; they are applicable only under conditions similar to those on which their development was based. To point out their limits, an analytical ("sliding block") model, for the prediction of the distance travelled by fine-grained material flows by taking into account (i) the (curved) geometry of the sliding surface; (ii) the evolution of the excess pore water pressures (generation, initially due to several phenomena and during the motion to the slope curvature, coupled to undrained and oedometric conditions; dissipation, due to consolidation); (iii) physical and mechanical parameters of the sliding material; (iv) the mass variation due to possible erosion or deposition processes, is developed and proposed. The model allows to evaluate the effects of these factors/phenomena (neglected by the conventional empirical criteria) mainly affecting the kinematics of fine-grained material flows and to interpret the results obtained by applying the main empirical relationships. Finally, through the results of back analyses of some documented cases, an original empirical law to predict the runout length is elaborated.
\end{abstract}

Keywords: Fine Grained Material Flows; Runout Length; Empirical Relationships; Numerical Modeling

\section{Introduction}

An essential part of any landslide risk assessment is the prediction and the quantitative estimation of the travel distance (i.e. "runout" length). To this purpose, several empirical relationships have been proposed [1-4]. Their development is based on field observations and on the correlation between parameters characterizing the landslide (i.e. the volume $V$ of the sliding mass), the path (i.e. local morphology, presence of obstructions) and the travel distance. The main empirical criteria are analytically expressed by different functional relationship applied to compute the 'angle of reach' $\beta$, conventionally defined as [5]:

$\tan (\beta)=\frac{\mathrm{H}}{\mathrm{L}}(1)$

$H$ and $L$ being the difference in elevation between the highest point of the granular mass before sliding and the more advanced point of deposit after sliding, and the total travel distance of granular flow projected on a horizontal plane, respectively.
According to main empirical relationships, the tangent of $\beta$ only depends on the involved volume $V$ (expressed in $\mathrm{m}^{3}$ ). In particular, through a careful analysis of data concerning 204 landslides in soil and rock materials (their volume mainly ranging between $10^{2}$ and $10^{6} \mathrm{~m}^{3}$ ), Corominas [1] proposed the following relationship:

$\frac{\mathrm{H}}{\mathrm{L}}=0.897 \cdot \mathrm{V}^{-0.085}(2)$

Applicable to all types of landslides (e.g. rock avalanches, debris flows, mudflows), with regression coefficient $R^{2}=0.63$. Specifically, for mudslides, Corominas [1] developed the following law:

$\frac{\mathrm{H}}{\mathrm{L}}=0.611 \cdot \mathrm{V}^{-0.070}\left[\mathrm{R}^{2}=0.65\right](3)$

From dataset concerning subaerial, volcanic, non-volcanic and submarine landslides, Legros [3] proposed the following relationship: 
$\frac{\mathrm{H}}{\mathrm{L}}=5.64 \cdot \mathrm{V}^{-0.190}(4)$

Applicable to lahars or mudflows $\left(\mathrm{R}^{2}=0.81\right)$. Finlay., et al. [6] showed that the travel distance $\mathrm{L}$ reasonably correlates with the downslope angle $\alpha_{1}$ below the source area. Specifically, through the statistical analysis of data concerning the major Hong Kong landslide events which involved materials mainly composed of loose dumped silty sands and sandy silts with low clay content, Finlay et al. [6] proposed the following relationship:

$\frac{H}{L}=0.78\left(\tan \alpha_{1}\right)^{0.5}(5)$

Applicable to small landslides $\left(V<500 \mathrm{~m}^{3}\right)$, with $\mathrm{R}^{2}=0.85$. Hunter and Fell [4] revised this work using more selective good quality data related to 350 rapid landslides $\left(V \in[20,26000] \mathrm{m}^{3}\right)$ and improving eq. (5) through the following relationship:

$\frac{\mathrm{H}}{\mathrm{L}}=0.54 \tan \alpha_{1}+0.147(6)$

Applicable to 'confined' flowslides, mudslides and debris flows $\left(\mathrm{R}^{2}=0.85\right)$. Furthermore, Hunter and Fell [4] correlated the ratio $H / L$, normalized against the tangent of $\alpha_{1}$, to the volume $V\left(\mathrm{R}^{2}=\right.$ 0.62):

$(\mathrm{H} / \mathrm{L}) /\left(\tan \alpha_{1}\right)^{0.42}=1.09 \cdot \mathrm{V}^{-0.109}(7)$

The comparison between the considered empirical relationships has been carried out (Figure 1). For fixed/assigned values of $V, H$ and $\alpha_{1}$, a remarkable difference between the computed values of $L$ is observed (Figure 1). Because of this large variability, although the empirical relationships are simple and rapid to use, they with difficulty may safely be applied, even if preliminarily, to evaluate the runout length. These relationships should be only applied under physical conditions similar to those related to the analysed case studies on which their development is based.

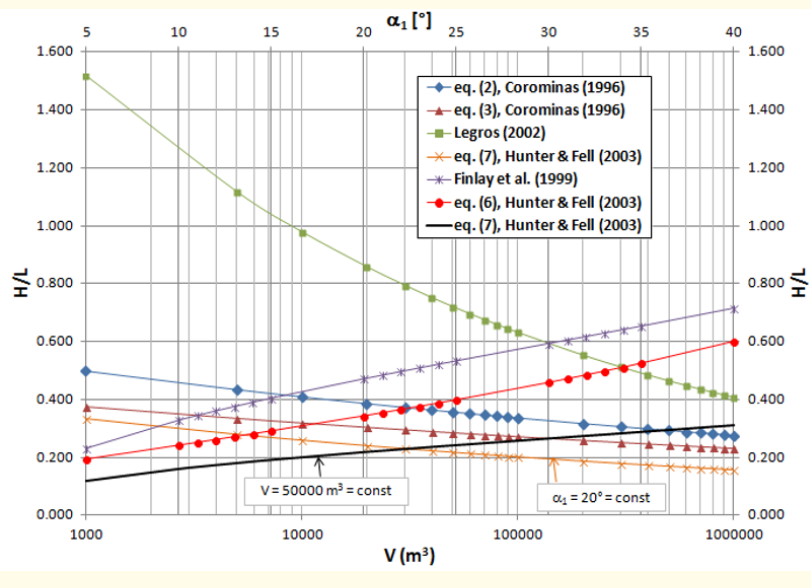

Figure 1: Empirical relationships: a) $H / L$ vs $V$; b) $H / L$ vs $\alpha_{1}$.
Furthermore, in addition to $H, V$ and $\alpha_{1}$, the role of factors as pore water pressures, the possible mass variability along the motion and the (curvilinear) geometry of the sliding surface, should be considered for reliable estimations of $L$ [7].

Main phenomena affecting the motion of fine-grained material flows

According to field observations and measurements [8], the triggering mechanism and successive sliding/propagation of finegrained material flows considerably depend on the generation (and possible dissipation due to consolidation phenomena along the motion) of excess pore water pressures. The excess pore water pressures can be generated by (i) cyclic shear strains induced by earthquakes; (ii) deposition of consolidating (initially liquefied) granular materials; (iii) rapid accumulation of rainwater in soil layers affected by a low permeability; (iv) seepage flow in boundary materials; (v) redistribution of the total stresses caused by internal mechanisms of rupture or reactivation [9]; (vi) compressive deformation of flow body associated with local variations of the slope of the sliding surface or due to centrifugal force acting along a curvilinear path $[10,11]$; (vii) consolidation processes under undrained and oedometric conditions [12]; (viii) discharge of debris producing rapid loading at rear of sliding mass where basal slip surface inclined fairly steeply downwards [8].

The considerable shear strength reduction due to the generation of the excess pore water pressures is the main reason of high mobility of unstable material volumes, even on very gentle slopes; furthermore, high pore water pressures can induce the partial or complete liquefaction of the soil $[13,14]$. Conversely, the consolidation process, especially affecting fine-grained material flows along the motion, may progressively reduce the pore water pressures and the corresponding increase of the shear strength reduces the travel distance.

Kinematics of fine-grained material flows can remarkably be influenced by the possible mass variations occurring along its motion, due to erosion or deposition processes [15]. Typically, the erosion phenomenon (mass rate $d m / d t>0$ ) mainly occurs at high elevation, induced by the high slope (up to an erosion critical slope $\beta_{e}$ ) and the great travel speed, and may cause considerable increments of volume or mass; the deposition $(d m / d t<0)$, caused by the slowdown due in turn to the reduction of slope $\left(<\beta_{\mathrm{e}}\right)$, downstream occurs. For fine materials, characterized by $d_{p}<0.02 \mathrm{~m}$, the energy dissipation due to grain collisions can be neglected [16].

\section{Modeling of fine-grained material flows}

Following the "block model" approach $[17,18]$, the formulation originally proposed by Hutchinson [19] has been considered and 
improved [7]. The model, previously proposed by the Authors, is herein shortly described.

The motion of a block (Figure 2) of total thickness $h$, with a basal saturated layer $\left(h-d_{\mathrm{w}}\right)$, and length $\mathrm{l}$, along an inclined (slope $\alpha_{1}$ ) channel (or mountain stream), is assumed to model a fine-grained material flow.

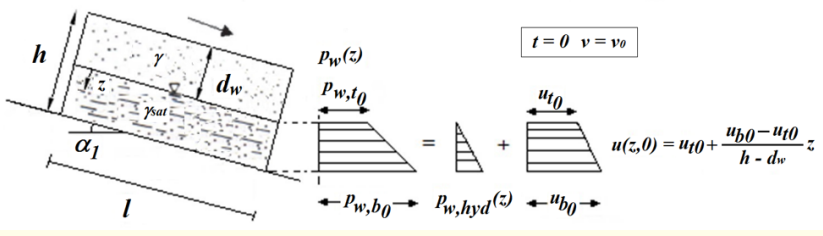

Figure 2: Problem's setting and basic assumptions concerning fine grained material flows modeling.

It is considered a trapezoidal initial pore water pressure distribution $\left(p_{w}(z)\right)$ within the basal saturated layer of thickness; the initial values $p_{w, t o}$ and $p_{w, b o}$ of pore water pressure, at the top and the base of the saturated layer, depend on the values of hydrostatic interstitial pressure $\left(p_{w, h y d}(z)=\gamma_{w z} \cdot \cos \alpha_{1}\right.$; with $\gamma_{w}=$ water unit weight $)$ and on the excess pore water pressure $u(z, t)(z$, normal to the sliding surface, directed downward, from the upper surface of the saturated soil layer; $u_{t 0}$ and $u_{b o}$, the initial values of the excess pore water pressure at the top and the base of the saturated layer, respectively). Thus, the resultant $U$ of the pore water pressures at the base of the sliding mass $\left(p_{w, b}(t)\right)$, is equal to the sum of the basal hydrostatic interstitial pressure $\left(p_{w, b, h y d}\right)$ and the basal excess pore water pressure at time $t\left(u\left(z=h-d_{w^{\prime}} t\right)=u_{b}(t): U=p_{w, b}(t) \cdot \Omega=\left(p_{w, b, h y d}+\right.\right.$ $\left.u_{b}(t)\right) \cdot \Omega \Omega=$ basal area).

If the involved material is not affected by dilatancy, the basal excess pore water pressures are dissipated during the motion due to consolidation process. Their evolution, referred to the case of impermeable horizontal base and drainage only through the upper surface of the saturated soil layer, may be simply described through the following dissipation law $u_{b}(t): u_{b}(t)=u_{b, 0} \cdot e^{-a t}$, where $a$ is a parameter related to the variables that govern the consolidation process of the involved material $\left(a=\pi^{2} c_{v} /\left(4 \cdot H^{2}\right), c_{v}\right.$ being the 1-D consolidation coefficient; $\mathrm{H}$, the drainage distance); $u_{b 0}$ can be evaluated as: $u_{b 0}=r_{0, b} \cdot u_{b, 0, \max }$, with $u_{b, 0, \max }=\left[\left(h-d_{w}\right) \gamma^{\prime}+d_{w} \cdot \gamma\right] \cdot \cos \alpha_{1}$ ( $\gamma$ ' is the submerged soil unit weight; $\gamma$ is the unsaturated soil unit weight) and $r_{0, b}<1$ to avoid the soil liquefaction. Particularly, the parameter $r_{0, b}$ may be i) evaluated as a function of the parameters $k_{\max }$ (the maximum earthquake-induced acceleration), OCR (the over consolidation ratio) and PI (the plasticity index), related to specific cyclic loading conditions (according to model by Matsuo et al. [20]; ii) assumed equal to $0.85 \div 0.95$ if soil consolidates under their own weight $[7,21]$.

Pore water pressure increments induced by the curvature of the sliding surface

If the sliding surface is geometrically described by a curvature $1 / r \neq 0$, the centripetal force $\left(=m \times s^{2} /(r(s))=m \times v^{2} /(r(s)), r(s)\right.$ $=$ curvature radius, $\mathrm{m}=$ mass of sliding material) occurs; this force modifies the normal resultant forces $(N)$ and $U$, as well as the global shear resistance force $\left(\mathrm{T}_{\max }\right)$. The progressive reduction of the slope of the sliding surface $\alpha(s)=\alpha_{-1}-s ; r, \alpha_{1}=\alpha(s=0)$ ) along the curved path induces the decrease of the driving force $(=m g \sin \alpha(s))$ and the increase of $N$. Therefore, the current value of the total normal force acting at the base of the sliding mass is expressed as follows:

$\mathrm{N}=\mathrm{mg} \cos \alpha(\mathrm{s})+\mathrm{m} \cdot \frac{\mathrm{v}^{2}}{\mathrm{r}}(8)$

Where is clearly recognizable the increase $\Delta N=m \cdot v^{2} / r$, associated with the curvature of the sliding surface and the velocity of the sliding granular mass. Furthermore, if the curvature assumes high values, the pore water pressure doesn't vary hydrostatically $[10,11]$ : a change of the direction of motion of a fluid particle (curvilinear path) induces an increase of the piezometric head and interstitial pressures: $p_{w}(z)=p_{w, h y d}(z)+\Delta p_{w, k}(v, r(z), z)$, with $\Delta \mathrm{p}_{\mathrm{w}, \mathrm{k}}(\mathrm{v}, \mathrm{r}(\mathrm{z}), \mathrm{z})=\gamma_{\mathrm{w}} \frac{\mathrm{v}^{2}}{\mathrm{r}(\mathrm{z}) \mathrm{g}} \mathrm{z} \wedge(g=$ gravity acceleration $)$, representing the increment or pore water pressure due to the curvature of the sliding surface, with $r(z)=r_{b}-h+z, r_{b}$ being the curvature radius at the base of the sliding block ( $r \cong r_{b}$, for shallow flows). According to above considerations, it is possible to write [11]:

$\frac{\mathrm{p}_{\mathrm{w}}(\mathrm{z})}{\mathrm{p}_{\mathrm{w}, \mathrm{b}, \mathrm{hyd}}}=\frac{\mathrm{z}}{\mathrm{h}} \cdot[1+\Psi(\mathrm{r}(\mathrm{z}), \mathrm{z})](9)$

being

$\Psi(\mathrm{r}(\mathrm{z}), \mathrm{z})=\frac{\Delta \mathrm{p}_{\mathrm{w}, \mathrm{k}}(\mathrm{r}(\mathrm{z}), \mathrm{z})}{\mathrm{p}_{\mathrm{w}, \mathrm{b}, \mathrm{hyd}}}=\frac{\mathrm{v}^{2}}{\mathrm{r}(\mathrm{z}) \mathrm{g} \cos \alpha}(10)$

If $r>>h$ (i.e. for shallow flows), the increment of the pore water pressure (eq. (10)) can be neglected if compared with the hydrostatic one.

An additional coupled effect related to the curvature of the sliding surface arises, especially for fine grained soils (small $c_{v}$ values), if the increase of total normal stresses within the saturated mass together with the 'almost' undrained condition, that may take place during the short interval time elapsing during the curved path, are 
taken into account. If elastic mechanical behaviour of the saturated mass is assumed, an additional pore water pressure increase could arise: $\Delta p_{w, \Delta N}(z)=C_{p w} \cdot \Delta \sigma_{\Delta N}(z), C_{p w}$ (generally equal to 1 for saturated materials) being the pore water pressure parameter for loading processes under oedometric and undrained conditions [12]; $\Delta \sigma_{\Delta N^{\prime}}$ the increase of total normal stresses related to the curvature of the sliding surface (the increment of $N$ due to possible increase of the mass is neglected):

Thus, at the base $\left(\mathrm{z}=\mathrm{h}-\mathrm{d}_{\mathrm{w}}\right)$ of the sliding mass,

$\Delta \mathrm{p}_{\mathrm{w}, \mathrm{b}, \mathrm{k}}=\Delta \mathrm{p}_{\mathrm{w}, \mathrm{k}}\left(\mathrm{v}, \mathrm{r}(\mathrm{z}), \mathrm{z}=\mathrm{h}-\mathrm{d}_{\mathrm{w}}\right)=\gamma_{\mathrm{w}} \frac{\mathrm{v}^{2}}{\mathrm{rg}}\left(\mathrm{h}-\mathrm{d}_{\mathrm{w}}\right)$

$\Delta \mathrm{p}_{\mathrm{w}, \mathrm{b}, \Delta \mathrm{N}}\left(\mathrm{z}=\mathrm{h}-\mathrm{d}_{\mathrm{w}}\right)=\mathrm{C}_{\mathrm{pw}} \cdot \Delta \sigma_{\mathrm{b}, \Delta \mathrm{N}}$

$\Delta \sigma_{b, \Delta N}$ being the increase of basal total normal stresses $\left(=\Delta \sigma_{\Delta N}\right.$ $\left.\left(z=h-d_{w}\right)\right)$.

Under these assumptions, the resultant $U$ of the pore water pressure at the base of the sliding mass $\left(p_{w, b}\right)$ should be rewritten as follows:

$$
\begin{aligned}
& \mathrm{U}=\left[\mathrm{p}_{\mathrm{w}, \mathrm{b}, \text { hyd }}+\mathrm{u}_{\mathrm{b}}(\mathrm{t})+\Delta \mathrm{p}_{\mathrm{w}, \mathrm{b}}\right] \times \Omega(12) \\
& \text { being } \Delta \mathrm{p}_{\mathrm{w}, \mathrm{b}}=\Delta \mathrm{p}_{\mathrm{w}, \mathrm{b}, \mathrm{k}}+\Delta \mathrm{p}_{\mathrm{w}, \mathrm{b}, \Delta \mathrm{N}} .
\end{aligned}
$$

\section{Mass variation processes}

The mass $(\mathrm{m})$ of granular flows may vary along their motion due to erosion/deposition processes. The following general expression for $m(=m(t))$ can thus be assumed [22]:

$m(t)=m(x(t))=m_{-0}+\mu^{\prime}\left(x-x_{-e}\right)$

$m_{0}(\mathrm{~kg})$ being the initial mass $\left(=\left[d_{w} \cdot \gamma+\left(h-d_{w}\right) \cdot \gamma_{-s a t}\right] l \cdot \mathrm{B}_{c} / \mathrm{g}, \mathrm{B}_{\mathrm{c}}=\right.$ width of the confined granular flow); $\mu^{\prime}(\mathrm{kg} / \mathrm{m})$, the erosion/deposition rate $\left(\mu^{\prime}>0\right.$, erosion; $\mu^{\prime}<0$, deposition); $x_{e^{\prime}}$ the abscissa for which the erosion/deposition process starts; in particular, several Authors [15,23] suggested:

$$
\mu^{\prime}=\left\{\begin{array}{l}
\mu_{\mathrm{e}}^{\prime}>0, \text { if } \alpha(\mathrm{s})>\beta_{\mathrm{e}} \\
\mu_{\mathrm{d}}^{\prime}<0, \text { if } \alpha(\mathrm{s})<\beta_{\mathrm{e}}
\end{array}\right.
$$

$\beta_{e}$ being the erosion critical slope (as previously introduced) generally ranging between $8^{\circ}-14^{\circ} ; \beta_{e}$ can also be evaluated through the following relationship [24]:

$\beta_{\mathrm{e}}=\operatorname{atan}\left[\tan \varphi^{\prime} \cdot\left(1-2 \cdot \frac{\gamma_{\mathrm{w}}}{\gamma_{\mathrm{bed}}} \cdot \frac{1}{1+\frac{\gamma^{*}}{\gamma_{\text {bed }}}}\right)\right]$

$\gamma_{\text {bed }}$ being the specific weight of the material lying on the bed of the channel (typically, $18-20 \mathrm{kN} / \mathrm{m}^{3}$ ); $\gamma_{w^{\prime}}$ previously defined; $\gamma^{*}$ $\left(=\left[d_{w} \cdot \gamma+\left(h-d_{-w}\right) \cdot \gamma_{s a t}\right] / h\right)$, the average (according to factor $\left.S\right)$ unit weight of the sliding granular block; $\varphi^{\prime}$, the basal friction angle.

From measurements of yield rate [15], defined as the volume eroded (in $\mathrm{m}^{3}$ ) per meter of the path length, related to approximately 1000 reaches of 300 mudflow and (sand, silt, debris) flowslide events, it is possible to define a range of typical values for $\mu$ '. In particular, the most frequent measured values of the yield rate fall in the range $0 \div 5 \mathrm{~m}^{3} / \mathrm{m}$ [25]; thus, by assuming an (typical) average value of granular flow density of $1800 \mathrm{~kg} / \mathrm{m}^{3}$ [26], the admissible values for $\mu^{\prime}$ fall in the range $0 \div 9 \cdot 10^{3} \mathrm{~kg} / \mathrm{m}$, approximately. Absolute value of $\mu_{d}{ }^{\prime}(<0)$ is generally assumed equal to $\mu_{e}$ '.

\section{Governing equation}

If the mass $(m)$ of the sliding block vary along its motion due to erosion/deposition processes, the law's motion is generally expressed as follows:

$$
\mathrm{F}=\frac{\mathrm{d}(\mathrm{m}(\mathrm{t}) \cdot \mathrm{v}(\mathrm{t}))}{\mathrm{dt}}-\mathrm{w}^{*} \frac{\mathrm{d}(\mathrm{m}(\mathrm{t}))}{\mathrm{dt}}(16)
$$

$v$ being the velocity of the block; $w^{*}$, the velocity of the incorporated or lost mass. The resultant $F$ of forces acting on the block is expressed as follows:

$$
F=m g \sin (\alpha)-T_{\max }(17)
$$

$\alpha$ being the angle of slope of the sliding surface; $T_{\max }$ the shear resistance force (neglecting cohesion):

$T_{\max }=(N-U) \cdot \tan \varphi^{\prime}(18)$

For fine-grained materials (sand, silt, clay), the energy dissipation due to grain collisions can be neglected [7]. If the rate $w^{*}$ is assumed null [17], eq. (16) can be finally rewritten as:

$\mathrm{mg} \sin (\alpha)-(\mathrm{N}-\mathrm{U}) \cdot \tan \varphi^{\prime}=\mathrm{m}(\mathrm{t}) \frac{\mathrm{dv}(\mathrm{t})}{\mathrm{dt}}+\mathrm{v}(\mathrm{t}) \frac{\mathrm{d}(\mathrm{m}(\mathrm{t}))}{\mathrm{dt}}$

Thus, eq. (19) can be more generally rewritten as:

$$
\begin{aligned}
& \ddot{\mathrm{s}}+\dot{\mathrm{s}}^{2}\left\{\frac{1}{\mathrm{~m}(\mathrm{~s}(\mathrm{t}))} \frac{\mathrm{d}(\mathrm{m})}{\mathrm{ds}}+\left[1-\frac{\left(\mathrm{d}_{\mathrm{w}} \cdot \gamma+\left(\gamma_{\mathrm{sat}} \gamma_{\mathrm{w}}\right) \cdot\left(\mathrm{h}-\mathrm{d}_{\mathrm{w}}\right)\right) \cdot \mathrm{l} \cdot \mathrm{B}_{\mathrm{c}}}{\mathrm{g} \cdot \mathrm{m}(\mathrm{s}(\mathrm{t}))}\right] \frac{\tan \varphi^{\prime}}{\mathrm{r}(\mathrm{s})}\right\}- \\
& \mathrm{g} \cdot\left[\sin \alpha(\mathrm{s})-\cos \alpha(\mathrm{s}) \tan \varphi^{\prime}\right]+-\left[\left(\gamma_{\mathrm{w}}\left(\mathrm{h}-\mathrm{d}_{\mathrm{w}}\right) \cdot \cos \alpha(\mathrm{s})+\mathrm{u}_{\mathrm{b}, 0} \mathrm{e}^{-\mathrm{at}}\right)\right. \\
& \left.\frac{\mathrm{l} \cdot \mathrm{B}_{\mathrm{c}}}{\mathrm{m}(\mathrm{s}(\mathrm{t}))}\right] \tan \varphi^{\prime}=0
\end{aligned}
$$

$s$ being the curvilinear abscissa. At time $t=0$, the block starts its sliding along a surface sloped $\alpha(s=0)=\alpha$, with initial speed $v=$ $v_{0}=0$. 
The governing equation (20) must be numerically integrated. However, under some simplified assumptions, eq. (20) can be also analytically solved [7].

The numerical solution of the ODE (20) is obtained by applying the Finite Difference Method (FDM); in particular, the governing ODE is discretized according to the Eulero scheme. The sliding surface can be schematized according to Figure 3; specifically, through: a) an arc of circumference; b) two planar surfaces $\left(L_{1}=\right.$ length of the first slope) linked by an arc of circumference $(1 / r \neq 0$ starting by $s=0$ ); c) two planar surfaces, i.e. $r \rightarrow \infty$.

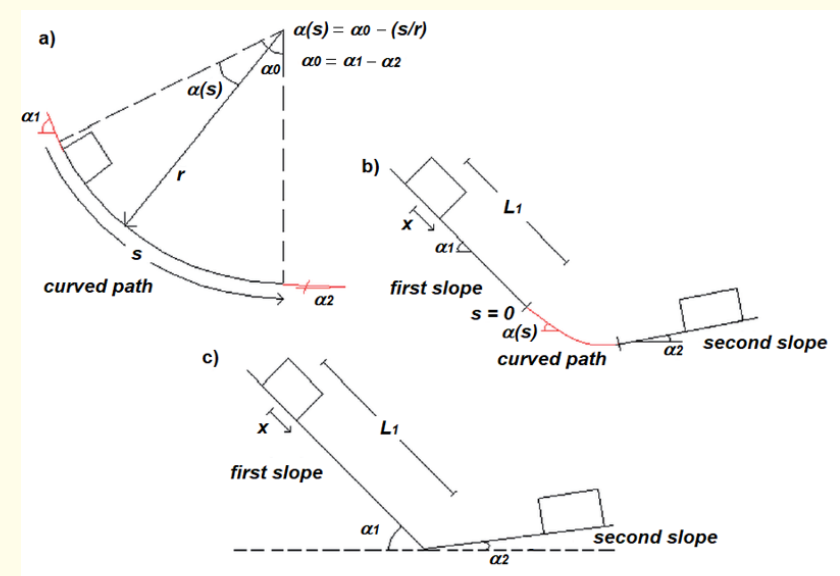

Figure 3: Possible geometries of the sliding surface.

Proposed model depends on several parameters $\left(r, r_{0, b^{\prime}} c_{v^{\prime}} S, \mu^{\prime}\right)$ pertaining to terrain and flow properties. Terrain properties include the geometry of the sliding surface and the erodibility of the channel bed (initial and final volume/mass of the involved material); flow properties include the dissipation of the excess pore water pressure (and the consolidation phenomena), the runout distance and the flow velocity. The sensitivity of the proposed numerical solution, in terms of travelled distance and speed evolution, to these parameters has already been evaluated, in detail by Authors, by taking into account their ranges of admissible values, previously investigated and defined [7].

Main limits of the proposed model lie in the simplified geometry of the sliding mass body (parallelepipedal shape), in the assignment of the law $u_{b}(t)$, in the assumptions of 1-D consolidation process and of linear-elastic behavior of the involved material, and in particular in the simplified schematization of the sliding surface (curvature of the basal surface only in the vertical plane). Regard- ing the simplified sliding surface (curvature in the vertical plane), the additional analytical difficulties arising to model the motion along curved and twisted channels (3D cases), as well as a rough estimate of the different mechanical effects, have been outlined [7]. However, the evaluation of these effects requires a detailed knowledge of the geometry of the sliding surface, in addition to other parameters which are not always easily evaluable. Alternatively, the detailed geometry (curvatures and torsion) of the sliding surface can be determined from cartographic bases (e.g. DEM, LIDAR data) that are difficult to find and not always available for the examined areas.

Role of geometrical, physical and mechanical variables on the runout length

The empirical relationships highlight/put in evidence the dependence of the runout length on the volume $(V)$ of the involved granular material and the geometry of the sliding surface (e.g. difference in elevation $H$ and first slope $\alpha_{1}$ ).

Through the proposed model, the (single and coupled) role played by additional factors, such as dissipation of initial excess pore water pressure, mass variation, slope curvature, on the mobility of fine-grained material flows and in particular on the ratio $H / L$, is investigated.

Effects of single factors. The following cases are analysed:

- Motion along planar surfaces $\left(r \rightarrow \infty, \Delta_{p w, b}=0\right.$, Figure 3c); partially saturated flow; constant mass $\left(\mu^{\prime}=0\right)$; dissipation of initial excess pore water pressure $\left(r_{0, b^{\prime}} u_{b, 0}\right)$ according to different values of $c_{v}$.

- $\quad$ Motion along planar surfaces $\left(r \rightarrow \infty, \Delta_{p w, b}=0\right.$, Figure $\left.3 \mathrm{c}\right)$; saturated flow $\left(d_{w}=0\right.$, Figure 2); initial excess pore water pressure $u=0$ (no consolidation and dissipation); variable mass according to different values of $\mu^{\prime}$.

- Motion along planar and curved (Figure $3 \mathrm{~b}$ ), according to different values of $\mathrm{r}\left(1 / r \neq 0, \Delta_{p w, b} \neq 0\right)$, surfaces; saturated flow $\left(d_{w}=0\right.$, Figure 2); initial excess pore water pressure $u=$ $O$ (no consolidation and dissipation); constant mass $\left(\mu^{\prime}=0\right)$.

\section{Case i}

The following input parameters: $\alpha_{1}=20^{\circ}, H=200 \mathrm{~m}\left(L_{1}=H /\right.$ $\left.\sin \left(\alpha_{1}\right)-l / 2\right), \alpha_{2}=0^{\circ}$ (planar sliding surfaces, Figure $3 \mathrm{c}$ ); $\varphi^{\prime}=27^{\circ}$; $\gamma=17 \mathrm{kN} / \mathrm{m}^{3} ; \gamma_{\text {sat }}=22 \mathrm{kN} / \mathrm{m}^{3} ; \mu^{\prime}=0 ; d_{w}=0.5 \cdot \mathrm{h} ; r_{0, b}=0.80$, are considered. 
For high values of volume $(V)$, the runout length becomes independent on $V$ and tends to assume a constant value. If $c_{v}$ decreases, $H / L$ also reduces and, in particular, for small values of $c_{v}\left(\leq 10^{-4}\right.$ $\mathrm{m}^{2} / \mathrm{s}$ ), the runout length is independent on volume $V$ (Figure 4 ).

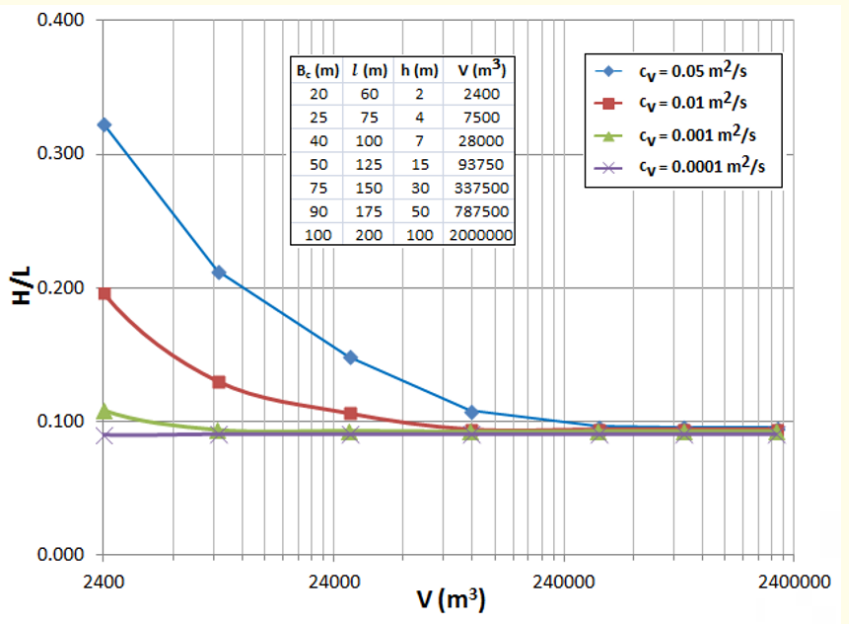

Figure 4: $H / L$ vs $V$, for different values of $c_{v}$.

Case ii

The following input parameters: $\alpha_{1}=35^{\circ}, H=250 \mathrm{~m}\left(L_{1}=H /\right.$ $\left.\sin \left(\alpha_{1}\right)-l / 2\right), \alpha_{2}=0^{\circ}$ (planar sliding surfaces, Figure $3 \mathrm{c}$ ); $\varphi^{\prime}=18^{\circ} ; \gamma$ $=17 \mathrm{kN} / \mathrm{m}^{3} ; \gamma_{\text {sat }}=22 \mathrm{kN} / \mathrm{m}^{3} ; d_{w}=0 ; r_{0, b}=0\left(\mu^{\prime}=\mu_{e}^{\prime}=\mu_{d^{\prime}}^{\prime}\right.$ only erosion processes), are considered.

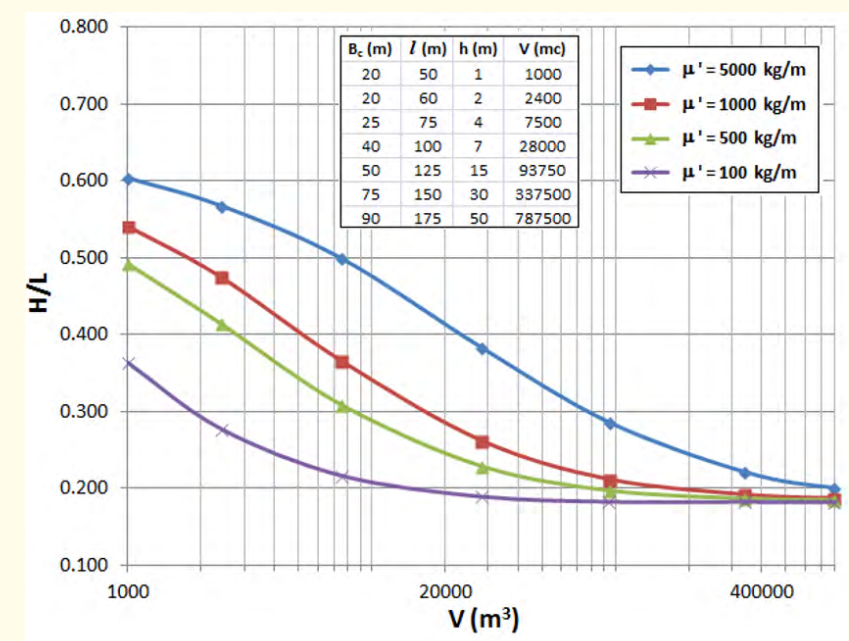

Figure 5: $H / L$ vs $V$, for different values of $\mu^{\prime}$.
If the erosion rate $\left(\mu^{\prime}=\mu_{e}^{\prime}\right)$ assumes high values, the ratio $H / L$ increases (Figure 5) due to a reduction of the runout length.

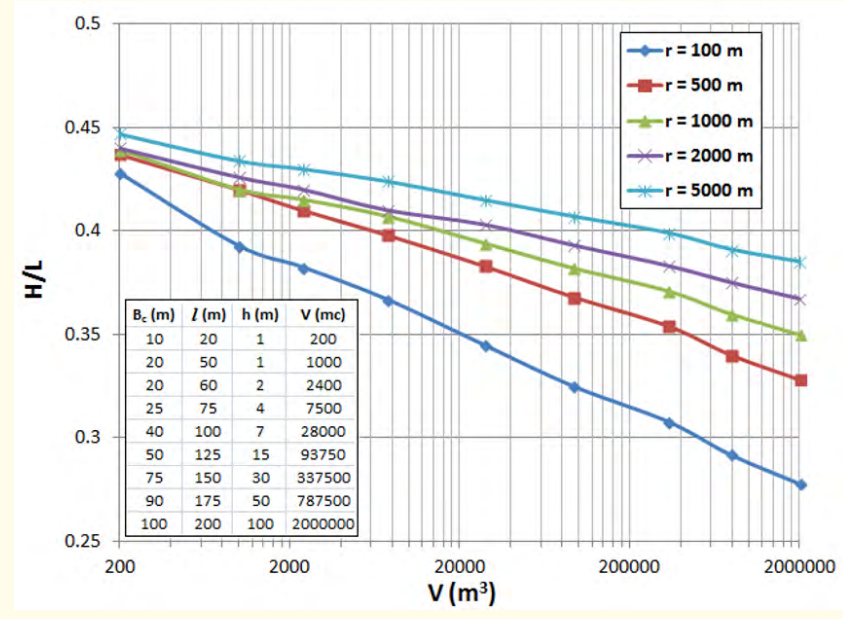

Figure 6: $H / L$ vs $V$, for different values of $r$ (curvature radius).

\section{Case iii}

The following input parameters: $\alpha_{1}=25^{\circ}, L_{1}=300 \mathrm{~m}, \alpha_{2}=0^{\circ}$ (planar and curved sliding surfaces, according to different values of curvature radius $r$, Figure $3 \mathrm{~b}$ ); $\varphi^{\prime}=33^{\circ} ; \gamma=14 \mathrm{kN} / \mathrm{m}^{3} ; \gamma_{\text {sat }}=19$ $\mathrm{kN} / \mathrm{m}^{3} ; d_{w}=0.5 \cdot h ; r_{0, b}=0 ; \mu^{\prime}=\mu$, are considered.

It is observed that the ratio $H / L$ increases if the volume $V$ of the sliding mass decreases and the curvature radius $r$ increases, for fixed volume $V$ (Figure 6). If $r$ increases, the pore water pressure increments $\Delta p_{w, b, \Delta N^{*}} \Delta p_{w, b, k}$ (depending on the square of velocity), due to slope curvature coupling undrained and oedometric conditions, decrease but they persist for a higher travelled distance along the curved path. Furthermore, for small values of $V, H / L$ becomes almost independent on $r$ and seems to tend to a specific value.

\section{Effects of coupled factors}

The following input parameters are selected: $\alpha_{1}=25^{\circ}, L_{1}=400$ $m, \alpha_{2}=0^{\circ} ; \varphi^{\prime}=30^{\circ} ; \gamma=18 \mathrm{kN} / \mathrm{m}^{3} ; \gamma_{s a t}=23 \mathrm{kN} / \mathrm{m}^{3} ; d_{w}=0.5 \cdot \mathrm{h} ; r_{0, b}=$ 0.9 and

- $\quad r=3000 \mathrm{~m}$ (planar and curved sliding surfaces, Figure $3 \mathrm{~b}$ ); $c_{v}$ $=10-5 \mathrm{~m}^{2} / \mathrm{s} ; \mu^{\prime}=500 \mathrm{~kg} / \mathrm{m}\left(=\mu_{e}^{\prime}=\mu_{d^{\prime}}^{\prime}\right.$ only erosion processes are simply considered)

- $\quad r=100 \mathrm{~m}$ (planar and curved sliding surfaces, Figure $3 \mathrm{~b}$ ); $c_{v}$ $=10-7 \mathrm{~m}^{2} / \mathrm{s} ; \mu^{\prime}=1000 \mathrm{~kg} / \mathrm{m}\left(=\mu_{e}^{\prime}=\mu_{d^{\prime}}^{\prime}\right.$ only erosion processes are simply considered) 
- $\quad r=5000 \mathrm{~m}$ (planar and curved sliding surfaces, Figure 3); $c_{v}$ $=10-2 \mathrm{~m}^{2} / \mathrm{s} ; \mu^{\prime}=2000 \mathrm{~kg} / \mathrm{m}\left(=\mu_{e}^{\prime}=\mu_{d^{\prime}}^{\prime}\right.$ only erosion processes are simply considered)

For small values of the consolidation coefficient $c_{v}\left(<10^{-4} \mathrm{~m}^{2} / \mathrm{s}\right)$, if the erosion processes and slope curvature are also considered, the ratio $H / L$ depends on $V$ (case a), Figure 7 ), in contradiction to previously analyzed single effects of $c_{v}$ (Figure 4). If the erosion rate $\mu^{\prime}$ increases and a reduction of curvature radius is also imposed, $H / L$ decreases (case b), Figure 7 . Higher values of $H / L$ can be obtained if high values of $r, c_{v^{\prime}} \mu^{\prime}$ are simultaneously assumed (case c), Figure 7.

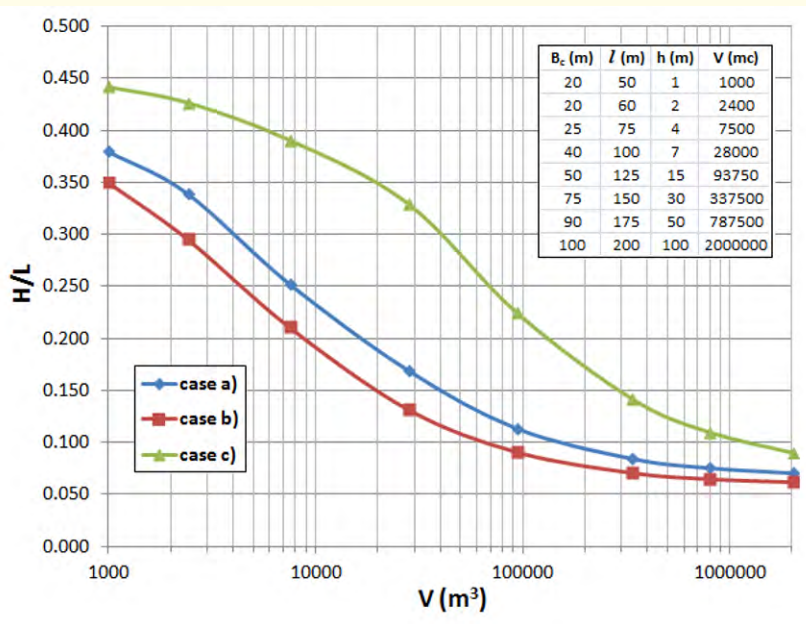

Figure 7: $H / L$ vs $V$, for different values of parameters $r, c_{v} \mu^{\prime}$.

The functional relationship between the computed ratio $H / L$ and the volume $V$ is shown in Figure 8; the best fitting of the results obtained through the proposed model is expressed through the following relationship: $H / L \propto V^{-0.24}$, resembling the relationship (eq. 4) proposed by Legros [3], approximately $\left(H / L \propto V^{-0.19}\right)$.

Proposed semi-empirical relationship to estimate the mobility of fine-grained material flows

Previous parametrical analyses show the dependence of the ratio $H / L$, in addition to the volume $V$ and downslope angle $\alpha_{1}$ (only variables considered in the main empirical criteria), on the factors such as $r, c_{\gamma^{\prime}} \mu^{\prime}$ (erosion rate); in particular, it is possible to write:

$\frac{\mathrm{H}}{\mathrm{L}}=\mathrm{f}\left(\mathrm{V}^{-0.24}, \tan \alpha_{1}, \mu^{\prime}, \mathrm{r}, \mathrm{c}_{\mathrm{v}}\right)$

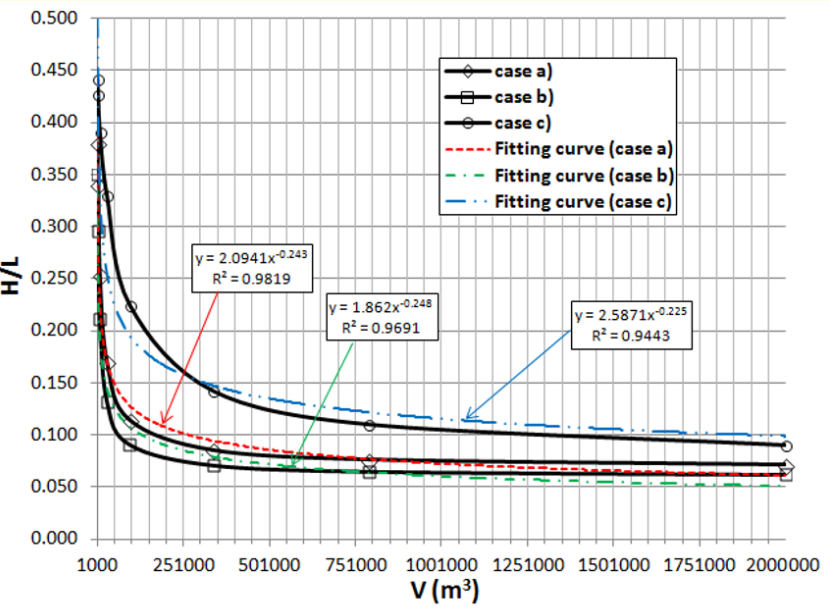

Figure 8: $H / L$ vs $V$, for different values of parameters $r, c_{v^{\prime}} \mu^{\prime}$ : fitting curves.

Thus, the following relationship is proposed:

$\frac{\mathrm{H}}{\mathrm{L}}=\mathrm{C}_{0}+\mathrm{C}_{1} \cdot \mathrm{V}^{-0.24}+\mathrm{C}_{2} \cdot \tan \alpha_{1}+\mathrm{C}_{3} \cdot \mu^{\prime}+\mathrm{C}_{4} \cdot \mathrm{r}+\mathrm{C}_{5} \cdot \mathrm{c}_{\mathrm{v}}$

The multiplier coefficients $C_{0^{\prime}} C_{1^{\prime}}, C_{2^{\prime}} C_{3^{\prime}} C_{4^{\prime}} C_{5}$ can be estimated by applying the multiple linear regression method to field data or results of simulations deriving from back analyses of real cases through analytical/numerical methods/models [7]. To estimate these coefficients, the following documented cases of mudflows are back analyzed through the proposed model: Quindici mudflow (Campania, Italy, 1998); Maokong mudflow (Taiwan, 2008); Aberfan flowslide (South Wales, 1966); Pedras Creek mudflow (Brazil, 1985). Geometrical, physical and mechanical parameters referring to the considered mudflow events are shown in Table 1.

The obtained results in terms of $L$ and then $H / L$ (best fitting the observed runout values), as well as the selected values of the parameters $c_{v} \mu^{\prime}$, are reported in Table 2 .

By applying the multiple linear regression method to the values of the variables $V, \tan \alpha_{1} \mu^{\prime}, r, c_{v^{\prime}}$ assigned in the back-analyses of the considered cases through the proposed model (Table 2), the following values of the multiplier coefficients are obtained: $C_{0}=-0.190$; $C_{1}=+3.00 ; C_{2}=+0.327 ; C_{3}=-1.35 \cdot 10^{-6} ; C_{4}=+4.61 \cdot 10^{-5} ; C_{5}=-0.019\left(\mathrm{R}^{2}=\right.$ 0.99 , coefficient of regression). Thus, eq. (22) can be rewritten as:

$\frac{\mathrm{H}}{\mathrm{L}}=-0.190+3.00 \cdot \mathrm{V}^{-0.24}+0.327 \cdot \tan \alpha_{1}-1.35 \cdot 10^{-6} \cdot \mu^{\prime}+4.61$
$10^{-5} \cdot \mathrm{r}-0.019 \cdot \mathrm{c}_{\mathrm{V}}(23)$ 


\begin{tabular}{|c|c|c|}
\hline \multicolumn{3}{|c|}{ Quindici Mudflow } \\
\hline Sliding surface & Physical and mechanical parameters & Observed runout length \\
\hline $\begin{array}{l}\text { The sliding surface is schematized by two planar surfaces } \\
\text { linked by an arc of circumference (Figure } 3 \mathrm{~b} \text { ): } \\
\alpha_{1}=35^{\circ} ; r=2500 \mathrm{~m} ; L_{1}=150 \mathrm{~m} ; \alpha_{2}=0^{\circ}\end{array}$ & $\begin{array}{l}V=40000 \mathrm{~m}^{3} ; d_{w}=0.25 \cdot h ; r_{0, b}=0.87 ; \\
\gamma=16 \mathrm{kN} / \mathrm{m}^{3} ; \gamma_{\mathrm{sat}}=21 \mathrm{kN} / \mathrm{m}^{3} ; \mathrm{h}=2 \mathrm{~m} ; \\
l=250 \mathrm{~m} ; B_{c}=80 \mathrm{~m} ; \varphi^{\prime}=25^{\circ}\end{array}$ & $L=1350 \mathrm{~m}$ \\
\hline \multicolumn{3}{|c|}{ Quindici Mudflows } \\
\hline Sliding surface & Physical and mechanical parameters & Observed runout length \\
\hline $\begin{array}{l}\text { The sliding surface is schematized by two planar surfaces } \\
\text { linked by an arc of circumference (Figure } 3 \mathrm{~b} \text { ): } \\
\mathrm{a}_{1}=28^{\circ} ; L_{1}=200 \mathrm{~m} ; \mathrm{r}=150 \mathrm{~m} ; \mathrm{a}_{2}=0^{\circ}\end{array}$ & $\begin{array}{l}l=40 \mathrm{~m} ; B_{c}=20 \mathrm{~m} ; d_{w}=0 \\
\gamma=19.1 \mathrm{kN} / \mathrm{m}^{3} ; V=2400 \mathrm{~m}^{3} ; h=3 \mathrm{~m} \\
\gamma_{\mathrm{sat}}=24 \mathrm{kN} / \mathrm{m}^{3} ; \varphi^{\prime}=30^{\circ} ; r_{0, b}=0.87\end{array}$ & $L=220 \mathrm{~m}$ \\
\hline \multicolumn{3}{|c|}{ Quindici Mudflows } \\
\hline Sliding surface & Physical and mechanical parameters & Observed runout length \\
\hline $\begin{array}{l}\text { The sliding surface is schematized by two planar surfaces } \\
\text { linked by an arc of circumference (Figure } 3 \mathrm{~b} \text { ): } \\
\alpha_{1}=12^{\circ} ; \alpha_{2}=0^{\circ} \mathrm{L}_{1}=220 \mathrm{~m} ; \mathrm{r}=2000 \mathrm{~m}\end{array}$ & $\begin{array}{l}d_{w}=0.1 \cdot h ; r_{0, b}=0.85 ; V=150000 \mathrm{~m}^{3} \\
\varphi^{\prime}=36^{\circ} ; h=2 \mathrm{~m} ; \gamma_{\mathrm{sat}}=19 \mathrm{kN} / \mathrm{m}^{3} \\
B_{c}=500 \mathrm{~m} ; \gamma=17 \mathrm{kN} / \mathrm{m}^{3} ; l=150 \mathrm{~m}\end{array}$ & $L=600 \mathrm{~m}$ \\
\hline \multicolumn{3}{|c|}{ Quindici Mudflows } \\
\hline Sliding surface & Physical and mechanical parameters & Observed runout length \\
\hline $\begin{array}{l}\text { The sliding surface is schematized by two planar surfaces } \\
\text { linked by an arc of circumference (Figure } 3 \mathrm{~b} \text { ): } \\
\alpha_{1}=29^{\circ} ; \alpha_{2}=0^{\circ} ; \mathrm{L}_{1}=370 \mathrm{~m} ; \mathrm{r}=2500 \mathrm{~m}\end{array}$ & $\begin{array}{l}d_{w}=0.5 \cdot h ; r_{0, b}=0.5 ; V=300000 \mathrm{~m}^{3} \\
\varphi^{\prime}=27^{\circ} ; B_{c}=40 \mathrm{~m} ; l=125 \mathrm{~m} ; \\
h=60 \mathrm{~m} ; \gamma=18 \mathrm{kN} / \mathrm{m}^{3} ; \gamma_{\text {sat }}=22 \mathrm{kN} / \mathrm{m}^{3}\end{array}$ & $L=1980 \mathrm{~m}$ \\
\hline
\end{tabular}

Table 1: Quindici, Maokong, Aberfan, Pedras Creek mudflows: geometrical, physical and mechanical parameters [18,27-29].

\begin{tabular}{|l|c|c|c|c|c|c|c|c|}
\hline \multicolumn{1}{|c}{ Event } & $\mathbf{L}[\mathbf{m}]$ & $\mathbf{H}[\mathbf{m}]$ & $\mathbf{H} / \mathbf{L}$ & $\mathbf{V}\left[\mathbf{m}^{3}\right]$ & $\tan \left(\boldsymbol{\alpha}_{\mathbf{1}}\right)$ & $\mu^{\prime}[\mathbf{k g} / \mathbf{m}]$ & $\mathbf{r}[\mathbf{m}]$ & $\mathbf{c}_{\mathbf{v}}\left[\mathbf{m}^{2} / \mathbf{s}\right]$ \\
\hline \multirow{3}{*}{ Quindici } & 1344 & 518 & 0.386 & 40000 & 0.70 & 1000 & 2500 & $1 \cdot 10^{-2}$ \\
\cline { 2 - 9 } & 1359 & 520 & 0.383 & 40000 & 0.70 & 2500 & 2500 & $2.5 \cdot 10^{-3}$ \\
\cline { 2 - 9 } & 1335 & 517 & 0.387 & 40000 & 0.70 & 5500 & 2500 & $5 \cdot 10^{-5}$ \\
\hline \multirow{3}{*}{ Maokong } & 258 & 111 & 0.431 & 2400 & 0.532 & 9000 & 150 & $5 \cdot 10^{-1}$ \\
\cline { 2 - 9 } & 261 & 111 & 0.426 & 2400 & 0.532 & 7000 & 150 & 1 \\
\hline \multirow{3}{*}{ Aberfan } & 616 & 88 & 0.142 & 150000 & 0.213 & 1000 & 2000 & $8.5 \cdot 10^{-5}$ \\
\cline { 2 - 9 } & 578 & 86 & 0.148 & 150000 & 0.213 & 100 & 2000 & $1 \cdot 10^{-4}$ \\
\cline { 2 - 9 } & 685 & 89 & 0.130 & 150000 & 0.213 & 6000 & 2000 & $5 \cdot 10^{-5}$ \\
\hline \multirow{2}{*}{ Pedras Creek } & 1931 & 493 & 0.255 & 300000 & 0.554 & 4000 & 2500 & $7.5 \cdot 10^{-3}$ \\
\cline { 2 - 9 } & 2073 & 493 & 0.238 & 300000 & 0.554 & 2500 & 2500 & $5 \cdot 10^{-2}$ \\
\hline
\end{tabular}

Table 2: Quindici, Maokong, Aberfan, Pedras Creek mudflows: results of numerical simulations.

\section{Comparisons with empirical relationships}

Comparison, in term of $L$ (total travel distance of granular flow projected on a horizontal plane), fixed $H(=200 \mathrm{~m})$, between the previously introduced empirical criteria and the proposed relationship is carried out (Figure 9-11). An appreciable agreement between eq. (2) and (3) proposed by Corominas [1], the relationship (4) by Legros [3], the criterion (7) by Hunter and Fell [4] and eq. (23) is observed. Through a suitable choice of parameters $r, c_{v}$, $\mu$ ', the proposed law can provide the same results of the 'conventional' criteria, approximately. 


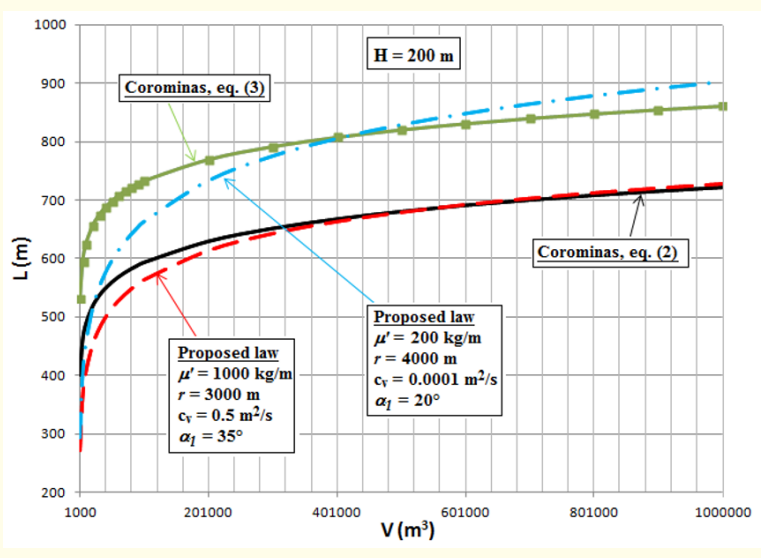

Figure 9: Comparison between the relationships by Corominas (1996) and the proposed law: $H / L v s V$.

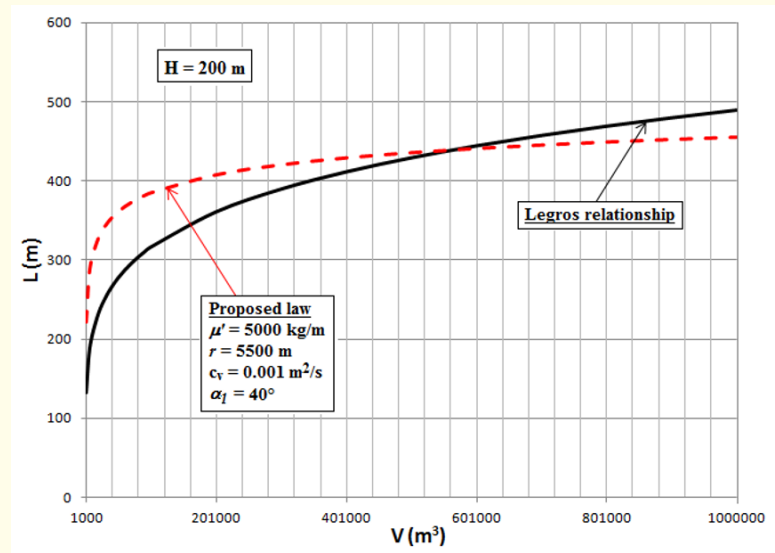

Figure 10: Comparison between the relationship by Legros (2002) and the proposed law: $H / L v s V$.

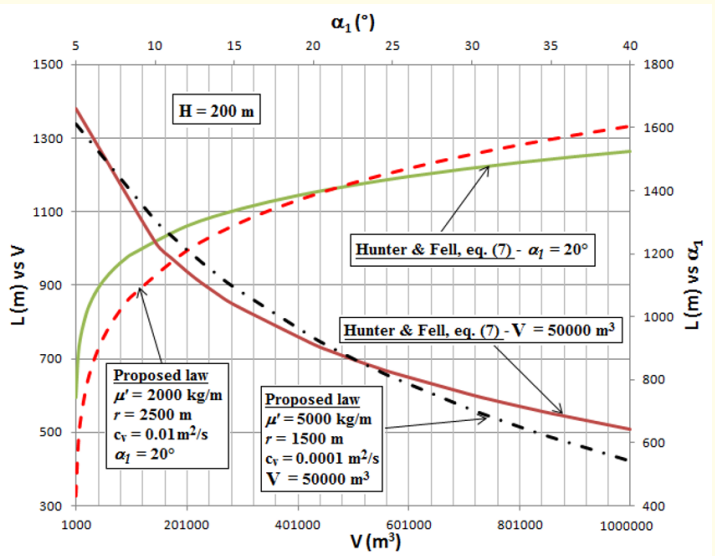

Figure 11: Comparison between the relationship by Hunter \& Fell (2003) and the proposed law: $L v s$; $L v s \alpha_{1}$.
Empirical relationships can be thus interpreted through the eq. (23). To this purpose, the Grohovo mudflow (Croatia, 1908) is considered and back analyzed.

\section{Application to grohovo mudflow}

A portion of the Rjeçina River near the city of Rijeka (Croatia) was affected by a 1908 mudflow event. The mudflow event was caused by heavy rainfall over a short period of time (estimated value was around $220 \mathrm{~mm}$ in $7 \mathrm{~h}$ ). Sedimentological analysis of the grain size and geotechnical tests on involved saturated material samples indicates that the silt and clay are dominant [30]. The consolidation coefficient was estimated at $6 \cdot 10-6 \mathrm{~m}^{2} / \mathrm{s}$ and the density of the soil mixture at $2100 \mathrm{~kg} / \mathrm{m}^{3}$. The initial volume of involved muddy materials was $132450 \mathrm{~m}^{3}$; during the propagation, the mudflow incorporated an additional volume, approximately doubling its mass [31].

Runout distance (L) of mudflow was estimated at $\cong 2000 \mathrm{~m}$ (Figure 12); depth of the mudflow was estimated at $33 \mathrm{~m}$. Path profile [31] and its schematization, through two planes linked by an arc of circumference (Figure $3 \mathrm{~b}$ ), are shown in Figure 12.

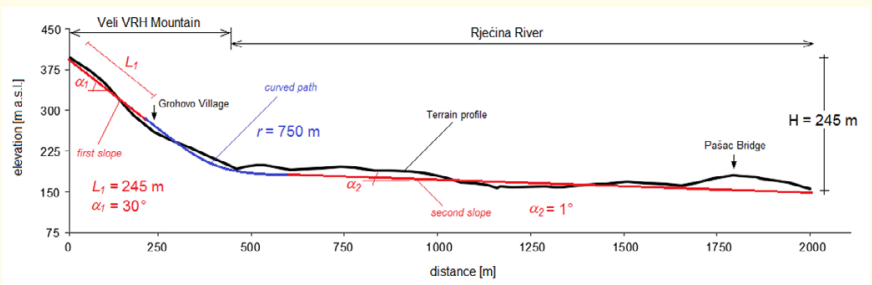

Figure 12: Grohovo mudflow: path profile and its schematization.

By applying the empirical relationships by Corominas (eqs. 2, 3), Legros (eq. 4) and Hunter and Fell (eq. 7) and the proposed law (eq. 23), the following results are obtained (Table 3).

Considered empirical criteria provide smaller values of runout

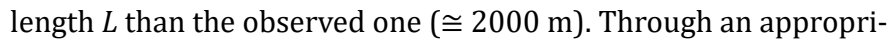
ate choice of parameters $r, c_{v}$ and in particular $\mu^{\prime}$, the proposed law allows to obtain a value of $L$ close to $2000 \mathrm{~m}$. It is worth noting that the assigned value $\mu^{\prime}=70000 \mathrm{~kg} / \mathrm{m}$ corresponds to an increase of volume equal to $80000 \mathrm{~m}^{3}$ ( $\cong 40 \mathrm{~m}^{3} / \mathrm{m}$, deriving from 70000 $\mathrm{kg} / \mathrm{m} / 1800 \mathrm{~kg} / \mathrm{m}^{3}$, with $1800 \mathrm{~kg} / \mathrm{m}^{3}=$ typical density of material lying on the bed channel), providing a final volume of $212450 \mathrm{~m}^{3}$, approximately equal to twice the initial volume of the involved material, as in situ observed. 


\begin{tabular}{|l|c|c|c|c|c|c|c|}
\hline \multicolumn{1}{|c|}{ Relationship } & $\mathbf{H}[\mathbf{m}]$ & $\mathbf{V}\left[\mathbf{m}^{\mathbf{3}}\right]$ & $\tan \left(\boldsymbol{\alpha}_{\mathbf{1}}\right)[\mathbf{~}$ & $\mu^{\prime}[\mathbf{k g} / \mathbf{m}]$ & $\mathbf{r}[\mathbf{m}]$ & $\mathbf{c}_{\mathbf{v}}\left[\mathbf{m}^{2} / \mathbf{s}\right]$ & $\mathbf{L}[\mathbf{m}]$ \\
\hline Proposed law, eq. (23) & 245 & 132450 & 0.577 & 70000 & 750 & 0.000006 & 2120 \\
\hline Corominas, eq. (2) & 245 & 132450 & - & - & - & - & 744 \\
\hline Corominas, eq. (3) & 245 & 132450 & - & - & - & - & 916 \\
\hline Legros, eq. (4) & 245 & 132450 & - & - & - & - & 408 \\
\hline Hunter and Fell, eq. (7) & 245 & 132450 & 0.577 & - & - & - & 1024 \\
\hline
\end{tabular}

Table 3: Grohovo mudflow: values of L obtained through the empirical and proposed relationships.

The values of $L$ computed through the empirical criteria can be obtained by applying the proposed law (Table 4) if specific values are assigned to geometrical and physical parameters $r, c_{v}$ and $\mu^{\prime}$, in particular, by imposing higher values of $c_{v}$ and $r$, and smaller values of $\mu$ '.

Values of $L$ computed through the relationship proposed by Legros [3] are obtained for remarkable higher values of $r$; thus, it seems to be applicable to events affected by a sliding surface for which the effects of curvature slope can be neglected. Furthermore, it seems to be appropriate to predict the mobility of landslides characterized by small variations of their mass and involving coarse-grained materials (high values of $c_{v}$ ). The other laws can be applicable to events affected by mass variations, slight curvature slope effects and values of $c_{v}$ corresponding to silty materials.

\begin{tabular}{|c|c|c|c|c|c|c|}
\hline \multicolumn{7}{|c|}{ Proposed law } \\
\hline $\mathbf{H}[\mathbf{m}]$ & $\mathbf{V}\left[\mathbf{m}^{3}\right]$ & $\tan \left(\boldsymbol{\alpha}_{\mathbf{1}}\right)$ & $\begin{array}{c}\mu^{\prime} \\
{[\mathbf{k g} / \mathbf{m}]}\end{array}$ & $\mathbf{r}[\mathbf{m}]$ & $\begin{array}{c}\mathbf{c}_{\mathbf{v}} \\
{\left[\mathbf{m}^{2} / \mathbf{s}\right]}\end{array}$ & $\mathbf{L}[\mathbf{m}]$ \\
\hline 245 & 132450 & 0.577 & 100 & 9000 & 0.01 & 415 \\
\hline 245 & 132450 & 0.577 & 40000 & 4500 & 0.005 & 745 \\
\hline 245 & 132450 & 0.577 & 50000 & 3500 & 0.001 & 910 \\
\hline 245 & 132450 & 0.577 & 55000 & 3000 & 0.0001 & 1023 \\
\hline
\end{tabular}

Table 4: Interpretation of empirical criteria: values of $L$ obtained through the proposed relationship.

In order to obtain reliable predictions, careful analyses of the (geometrical and physical) conditions in which they are applied, compared to those ones on which their development is based, are recommended [32-40].

\section{Concluding Remarks}

Rapid sliding of a fine - grained material is analysed by taking into account the curvature of the basal surface, the variation of its mass due to erosion processes as well as the evolution of basal pore water pressures.
To estimate the distance travelled by the material, an analytical ("block") model is developed and proposed. The governing equation, describing the sliding of the block, must be numerically integrated; however, it can be analytically solved under specific simplified assumptions.

Main limits of the proposed model lie in the simplified geometry of the sliding mass body (parallelepipedal shape) and of the sliding surface (curvature of the basal surface only in the vertical plane), in the assignment of the law $u_{b}(t)$, in the assumptions of 1-D consolidation process and of linear-elastic behavior of the involved material. However, the proposed model, even if based on simplified assumptions, through a suitable choice of the input parameters, allows to provide reliable estimations of the runout length. Improvements of the model referring to the mechanical behavior of the sliding material could be carried out. Specifically, its re-implementation by assuming an elastic-plastic rheological model is going to be considered.

The (single and coupled) effects of the excess pore water pressures, mass variation and slope curvature on the runout length $(H / L)$ have been parametrically evaluated. In particular, the wellknown ratio $H / L$ decreases if the erosion rate $\left(\mu^{\prime}\right)$, the consolidation coefficient $c_{v}$ and the curvature radius $r$ singly decrease. Opposite effects can be obtained by their coupling.

These factors are neglected in conventional empirical relationships. Although the empirical relationships are simple and rapid to use, the great variability of their results makes them applicable, with some difficulty, to preliminarily predict the runout length.

Results of back-analyses of some documented cases has allowed the elaboration of a semi-empirical law, through which the considered empirical relationships can be re-interpreted.

Finally, additional back-analysis has allowed to show that the results of the empirical relationships are specific solutions of the proposed semi-empirical law and, thus, to define/recommend their fields of applicability, in some extent. 


\section{Bibliography}

1. Corominas J. "The angle of reach as mobility index for small and large landslides". Canadian Geotechnical Journal 33.2 (1996): 260-271.

2. Rickenmann D. "Empirical Relationships for debris flows". Natural Hazard 19 (1999): 47-77.

3. Legros F. “The mobility of long-runout landslides”. Engineering Geology 63.3-4 (2002): 301-331.

4. Hunter G and Fell R. "Travel distance angle for 'rapid' landslides in constructed and natural soil slopes". Canadian Geotechnical Journal 40.6 (2003): 1123-1141.

5. Heim A. "Bergsturz und Menschenleben". Zurich: Fretz and Wasmuth Verlag (1932): 218.

6. Finlay PJ., et al. "Landslide risk assessment: prediction of travel distance". Canadian Geotechnical Journa 36.3 (1999): 556-562.

7. Federico F and Cesali C. "Coupled effects of pore water pressures evolution, slope curvature and mass variation on the kinematics of rapidly sliding fine-grained materials". International Journal of Geomechanics 17.10 (2017).

8. Hutchinson JN and Bhandari RK. "Undrained loading, a fundamental mechanism of mudflows and other mass movements". Geotechnique 21.4 (1971): 353-358.

9. Comegna $\mathrm{L}$ and Picarelli L. "The interplay between pore pressures and slope movements in fine-grained materials". Proc., 11th IACMAG, Turin. (2005).

10. De Marchi G. "Idraulica. Basi scientifiche e applicazioni tecniche". Ulrico Hoepli, Milano. (1961).

11. Siviglia A and Cantelli A. "Effect of bottom curvature on mudflow dynamics: theory and experiments". Water Resources Research 41 (2005): 1-17.

12. Lambe TW and Whitman RV. "Soil Mechanics". John Wiley and Sons (1969): 553.

13. Iverson RM., et al. "Debris-flow mobilization from landslides". Annual Review of Earth and Planetary Sciences 25 (1997): 85138.

14. Take WA and Beddoe RA. "Base liquefaction: a mechanism for shear-induced failure of loose granular slopes”. Canadian Geotechnical Journal 51 (2014): 496-507.
15. Hungr 0., et al. "Quantitative analysis of debris torrent hazard for design of remedial measures". Canadian Geotechnical Journal 21.4 (1984): 663-677.

16. Federico F and Cesali C. "An energy-based approach to predict debris flow mobility and analyze empirical relationships". $\mathrm{Ca}$ nadian Geotechnical Journal 52.12 (2015): 2113-2133.

17. Van Grassen W and Cruden DM. "Momentum transfer in the debris of rock avalanches". Canadian Geotechnical Journal 27.5 (1990): 698-699.

18. Erismann TH and Abele G. "Dynamics of Rockslides and Rockfalls". Springer (2001).

19. Hutchinson JN. "A sliding consolidation model for flow slides". Canadian Geotechnical Journa 23.2 (1986): 115-126.

20. Matsuo T., et al. "Cyclic stress-strain history and shear characteristics of clay". Journal of Geotechnical Engineering, ASCE 106.10 (1980): 1101-1120.

21. Major JJ. "Gravity-driven consolidation of granular slurriesImplications for debris-flow deposition and deposit characteristics". Journal of Sedimentary Research 70.1 (2000): 64-83.

22. Cannon SH and Savage WZ. "A mass-change model for the estimation of Debris-flow runout". Journal of Geology 96.2 (1988): 221-227.

23. Ikeya H. "A method of designation for area in danger of debris flow". Erosion and Sediment transport in Pacific Rim, Steeplands". I.A.H.S., Publ. No. 132, Christchurch (1981): 576-588.

24. Takahashi T. "Debris flow. IAHR Monograph Series, Rotterdam, Balkema Publishers". (1991).

25. Hungr 0. "Flow slides and flows in granular soils". Proc., Int. Workshop on Occurrence and Mechanisms of Flow-Like Landslides in Natural Slopes and Earthfills, Sorrento, Picarelli ed., Kluwer Publishers (2004).

26. Costa JE. "Physical geomorphology of debris flow". Developments and Applications of Geomorphology Springer-Verlag Berlin Heidelberg. (1984): 268-317.

27. Revellino P., et al. "Velocity and runout simulation of destructive debris flows and debris avalanches in pyroclastic deposits, Campania region, Italy". Environmental Geology 45.3 (2004): 295-311. 
28. Kanji MA., et al. "Debris flow affecting the Cubatao Oil Refinery, Brazil". Landslides 5.1 (2008): 71-82.

29. Lee SHH and Widjaja B. "Phase concept for mudflow based on the influence of viscosity". Soils and Foundations 53.1 (2013): 77-90.

30. Zic E., et al. "A model of mudflow propagation downstream from the Grohovo landslide near the city of Rijeka (Croatia)". Natural hazards and earth system sciences 15.2 (2015): 293313.

31. Benac C., et al. "The origin of instability phenomena along the karst-flysch contacts". Rock Engineering in Difficult Ground Conditions-Soft Rocks and Karst-Vrkljan, ed. Taylor and Francis Group, London (2010): 757-761.

32. Biondi G., et al. "Effect of earthquake induced pore-water pressure in clay slopes". Proc., 4th International Conference on Earthquake Geotechnical Engineering, Thessaloniki, Greece. (2007).

33. Charles WWNG. "The state of the art centrifuge modelling of geotechnical problems at HKUST". Journal of Zhejiang University-Science A 15.1 (2014): 1-21.

34. Chian SC. "Empirical Excess Pore Pressure Dissipation Model for Liquefiable Sands". Proc., 6th International Conference on Earthquake Geotechnical Engineering, Christchurch, New Zealand. (2015).

35. Fernández-Merodo JA., et al. "Modelling the Portalet landslide mobility (Formigal, Spain)”. Proc., International Environmental Modelling and Software Society (iEMSs), (2008): 14761483.

36. Iwasaki T., et al. "A practical method for assessing soil liquefaction potential based on case studies at various sites in Japan". Proceedings of the Second International Conference on Microzonation (1978).

37. Lollino P., et al. "The Montaguto earthflow: a back analysis of the process of landslide propagation". Engineering Geology 170 (2014): 66-79.

38. Pastor M., et al. "Numerical modelling of fast slope movements". Modeling of Cohesive-Frictional Materials-Vermeer, Ehlers, Herrmann and Ramm (eds), Taylor and Francis Group, London (2004): 277-293.
39. Pellegrino A., et al. "Experiences of mudslides in Italy". Proc., Int. Workshop on Occurrence and Mechanisms of Flow-Like Landslides in Natural Slopes and Earthfills, Sorrento, Picarelli ed., (2004): 191-206.

40. Rauch AF., et al. "Centrifuge model test of a sand embankment built on saturated coal ash". Proc., World of coal ash Conference, Nasvhille. (2015).

\section{Volume 3 Issue 8 August 2019}

C All rights are reserved by Chiara Cesali and Francesco

Federico.

-

.

\author{
.
}

